\title{
Risk analysis by emission source strengths and wind directions of trace gases at Map Ta Phut Industrial Estate, Rayong province, Thailand
}

\author{
S. Pongpiachan ${ }^{1,2}$, V. Surapipit ${ }^{3}$, A. Ketratanakul ${ }^{4}$, \\ N. Wuttijak ${ }^{4} \&$ A. Pongnoppa ${ }^{4}$ \\ ${ }^{I}$ School of Social and Environmental Development, \\ National Institute of Development Administration (NIDA), Thailand \\ ${ }^{2}$ National Center of Excellence for Environmental and Hazardous Waste \\ Management-PSU Satellite Center, Prince of Songkla University, \\ Thailand \\ ${ }^{3}$ Pollution Control Department, \\ Ministry of Natural Resources and Environment, Thailand \\ ${ }^{4}$ IRPC PCL 555/2 Energy Complex, Thailand
}

\begin{abstract}
When air mass is flowing across the source area, it can lead to emissions and subsequently higher emissions of atmospheric concentrations of trace gases. It is well known that wind direction plays a significant role on atmospheric concentrations of persistent organic pollutants (POPs). While temperature and wind speed are obviously important parameters governing the atmospheric concentration of trace gases, these two parameters alone fail to entirely predict the atmospheric concentration of trace gases. Alternatively, wind direction may also be a controlling parameter for trace gas concentrations. Given that wind direction is measured as an angle $(\alpha)$ relative to true north (0), mean direction was determined by using trigonometric relations to determine the direction of the resultant of individual wind vectors. The emission source strength - wind direction relationship can be represented graphically by plotting R-value of (natural logarithm of partial pressure) vs against downwind angle $(\alpha)$ during the monitoring period. To apply this relationship, measured atmospheric concentrations must be expressed as partial pressures $(\mathrm{P})$, which can be converted through the use of the ideal gas law with a temperature correction. The
\end{abstract}


aims of this study are to statistically quantify the relationships between emission source strengths and downwind angles of sulphur dioxide, nitric oxide, nitrogen dioxide and ozone measured at five monitoring stations adjacent to Map Ta Phut Industrial Estate during 28/08/08 - 23/07/09.

R-values of gaseous $\mathrm{SO}_{2}, \mathrm{NO}, \mathrm{NO}_{2}, \mathrm{NO}_{\mathrm{x}}$ and $\mathrm{O}_{3}$ measured at POS and ITS tended to be higher than those of trace gases detected at other sites. Significant positive correlations $(\mathrm{p}<0.05)$ were found in downwind angles ranging from $180^{\circ}$ to $240^{\circ}$ for $\mathrm{SO}_{2}$ monitored at POS and ITS, suggesting the proper selection of these observatory sites as a part of risk analysis in a residential zone. In addition, the probability distribution analysis revealed that the emission source strengths of $\mathrm{SO}_{2}$ in POS and ITS have relatively low fluctuations comparing with those of other observatory sites.

Keywords: trace gases, wind direction, trigonometric, Mapthaput Industrial Estate, Thailand, risk analysis.

\section{Introduction}

Rapid industrialization and urbanization, high economic and population growth coupled with increasing motorization all contribute to air pollution problems in cities. With no exception, Map Ta Phut's air quality has been steadily deteriorating over the past ten years. This is, in part, seen in every city that intends to increase its economic growth, without considering the environmental impact. It is well known that Map Ta Phut Industrial Estate is the origin of Thailand's petrochemical industry. The first gas separation plant and the National Petrochemical Company were launched by Thai government in the early 1980s. The growth of the Map Ta Phut industrial estate has been very impressive both in terms of investment volume and total export profits. The major cause for the dramatically growth of this estate is due to upstream and downstream industry linkages by the oil refining and petrochemical units set up in the estate. In the interest of public health, the risks $v$ s benefits of the possible alternatives must be carefully considered. For instance, it might well be that the industrial emissions result in a certain number of patients suffering from adverse respiratory health outcomes per year. However, this risk must be balanced against the available alternatives of no industrial activities or even the pause in national economic expansion. Unless or until the creativity and technological developments offer superior methods for trapping those air pollutants, the policy makers have to make decision based on risk analysis.

Since toxic trace gases are continuously released into the atmosphere, raising concerns over the safety of both urban and suburban residents, it is therefore crucial to conduct the monitoring campaign of trace gases adjacent to the industrial estates of Map Ta Phut. The problem will be exacerbated in the future if no action is taken to mitigate the problem. Therefore, it is important to increase the capacity of the Pollution Control Department to protect and manage the environment and to improve the air quality of Thailand. This research is intended to assist the air quality management capacity coupled with the risk analysis of the largest industrial estates in Thailand, Map Ta Phut. This is 
consistent with the effort of the Thai Government under Section 78 of the 1997 Constitution to decentralize the central government and give local government the responsibility and opportunity to manage local issues, including air quality management. This is the first study to apply "cosine wind direction model" with one year data set of sulphur dioxide $\left(\mathrm{SO}_{2}\right)$, nitric oxide $(\mathrm{NO})$, nitrogen dioxide $\left(\mathrm{NO}_{2}\right)$ and ozone $\left(\mathrm{O}_{3}\right)$ collected at Map Ta Phut health center, Rayong province. In addition, this study will expand the database, and thus amend the scope of long term temporal trend analysis of trace gases in both industrial estate areas and residential zones. The most crucial attempt to conduct long term monitoring is to ensure that the application of observatory sites is available as a part of an early warning system.

\section{Methodology}

\subsection{Sampling site descriptions and monitoring period}

Air samples were collected at Thasit Observatory Station (TOS) (E:751375, N: $1400701 \mathrm{~N}$ ) in a rural agricultural area of Rayong province, located approximately $40 \mathrm{~km}$ northeast of Map Tha Put Industrial Estate (MIE) (Figure 1). Crop Research Center Observatory Station (CRS) (E: 731960, N: 1405653) and Map Tha Put Health Center Observatory Station (MHS) (E: $731960, \mathrm{~N}: 1405653)$ were selected because of its locations relatively close to MIE (i.e. $5 \mathrm{~km}$ for PTS and $10 \mathrm{~km}$ for MHS) and thus can be used as a representative of MIE residential zone. In addition, IRPC Technical School Observatory Station (ITS) (E: 751585, N: 1401373) and Pluakgate Temple

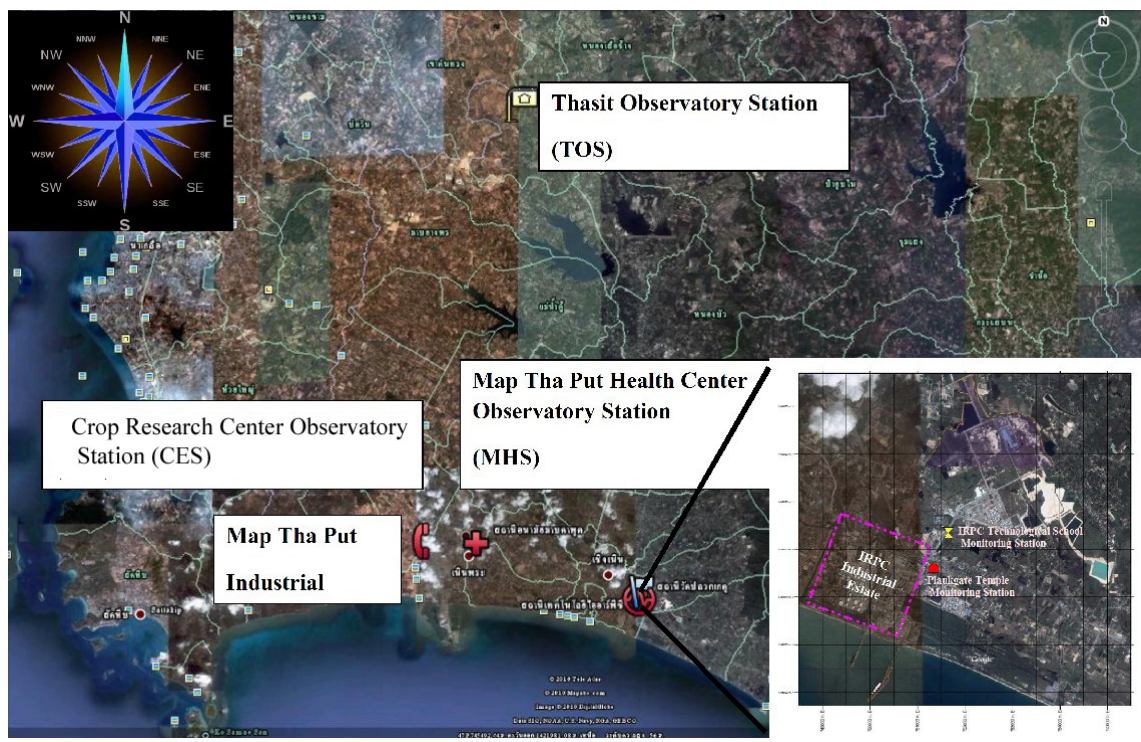

Figure 1: $\quad$ Location of air sampling site for this study. 
Observatory Station (POS) (E: 751375, N: 1400701) were chosen as accidental gas leakage warning stations and monitoring trace gas sites to expand the annual data base for pollution control department (PCD) of Thailand. In addition, ITS and POS are located approximately $2 \mathrm{~km}$ northeast and $1.3 \mathrm{~km}$ east of IRPC Industrial Estate (IIE) respectively. The trace gases at all observatory sites were measured during the period of 28/08/08 - 23/07/09 together with other meteorological parameters (i.e. temperature, wind speed, wind direction, air pressure, humidity, precipitation).

\subsection{Sample analysis}

\subsubsection{Trace gases analysis}

The measurements of trace gases were performed by using Syntec Spectras GC955 Series 600 BTEX Analyzer (Manufacturer: Synspec The Netherlands).

Computer controlled-embedded PC running proprietary software was Windows XP, 40 Gigabyte HD. BTEX compounds at 1 ppmv and Environics Model 6103 were used as calibration gas and dilution calibrator respectively. Four-point calibration (i.e. $0.25,0.75,2.00$ and $4.75 \mathrm{ppbv}$ ) was conducted for all trace gases. Chromatogram results from each $15-\mathrm{min}$ sample were written to a text file. Each text file contains 1 month of data and can be imported to EXCEL and ACCESS for review, processing and validation. Quality assurance was confirmed by using $2 \mathrm{ppbv}$ of standard VOC input to ensure that the precisions were lower than $\pm 15 \%$ and recovery ranged from $85 \%-115 \%$. In addition, the design specifications were described as follows (See Table 1 and Figure 2).

\subsection{Cosine wind direction (CWD) model}

When an air mass is flowing across a source area, it can lead to emissions and subsequently higher emissions of atmospheric concentrations of trace gases. It is well known that wind direction plays a significant role on atmospheric

Table 1: $\quad$ Design specifications of GC955 Series 600 BTEX analyzer.

\begin{tabular}{|c|c|}
\hline Carrier gas & $\mathrm{N}_{2}$ (Ultra High Purity) \\
\hline Preconcentrator & Tenax $G R$ \\
\hline GC-Based & Column: 15 m x 0.32 mm (ID) \\
& $-95 \%$ dimethylpolysiloxane; \\
& $5 \%$ diphenylpolysiloxane \\
& -2 -meter "stripper" column \\
& -13 -meter "analysis" column \\
\hline PID & $10.6 \mathrm{eV}, 50 \mu$ l measurement cell \\
\hline "Semi-continuous" & 15-minute analysis run time per sample \\
\hline 2 operating modes & - sample injection \\
& - sampling/Analysis \\
\hline Design keys & - preconcentrator \\
& -sampling piston \\
\hline
\end{tabular}




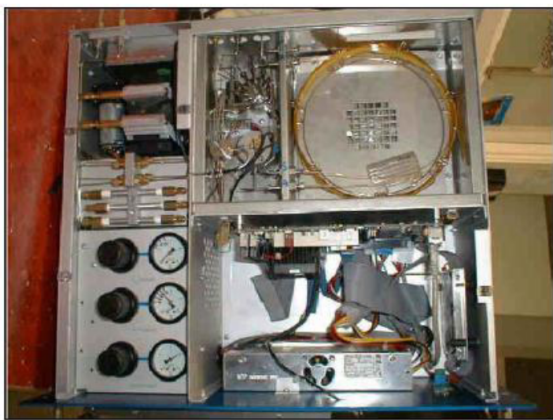

GC955 Inside Top view

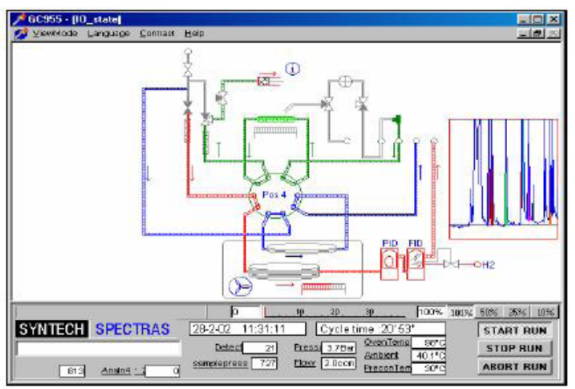

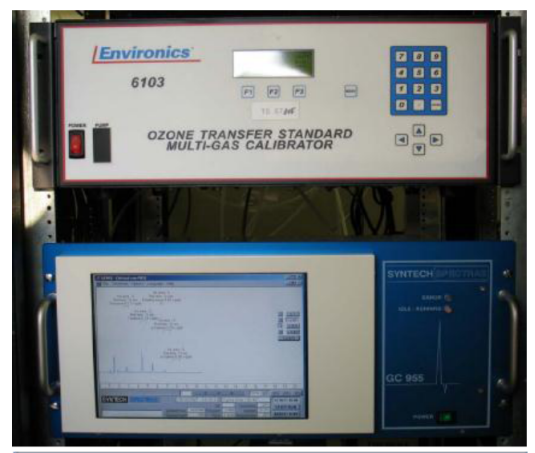

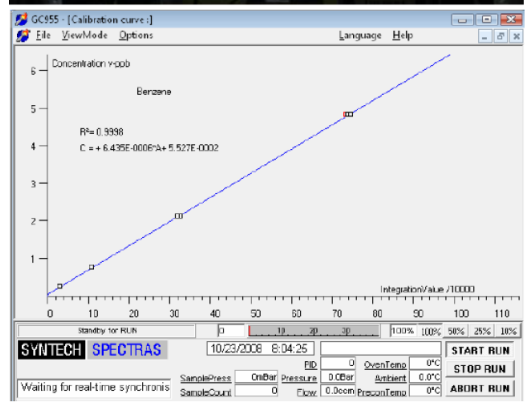

Figure 2: $\quad$ GC955 Series 600 BTEX analyzer.

concentrations of persistent organic pollutants (POPs) [1-5]. For instance, a four-fold increase in atmospheric polychlorinated biphenyls (PCBs) over southern Lake Michigan when air masses were traveling from a vector between Evanston, IL, and Gary, IN has been reported by Simcik et al. [5]. A similar four-fold increase in atmospheric concentrations was observed for gas-phase phenanthrene over the northern Chesapeake Bay when winds blew from Baltimore [3]. While temperature and wind speed are obviously important parameters governing the atmospheric concentration of trace gases, these two parameters alone fail to entirely predict the atmospheric concentration of trace gases. Alternatively, wind direction may also be a controlling parameter for trace gas concentrations.

Given that wind direction is measured as an angle relative to true north (0), mean direction was determined by using trigonometric relationships to determine the direction of the resultant of individual wind vectors [6]. To illustrate, consider a situation where maximum concentration is associated with a wind direction of $150^{\circ}$ (i.e. downwind angle $(\alpha)=150^{\circ}$, see Figure 3). If we calculate the angle of wind direction relative to the angle associated with maximum concentration, we get $\operatorname{Cos}(\mathrm{WD}-\alpha)$ values of $1,0,-1$ for the wind direction of $150^{\circ}, 240^{\circ}, 330^{\circ}$ respectively. In other word, the "downwind angle $(\alpha)$ " can be referred to the angle (relative to true north) at which maximum correlation between wind direction and trace gas concentrations occur [6]. The emission 


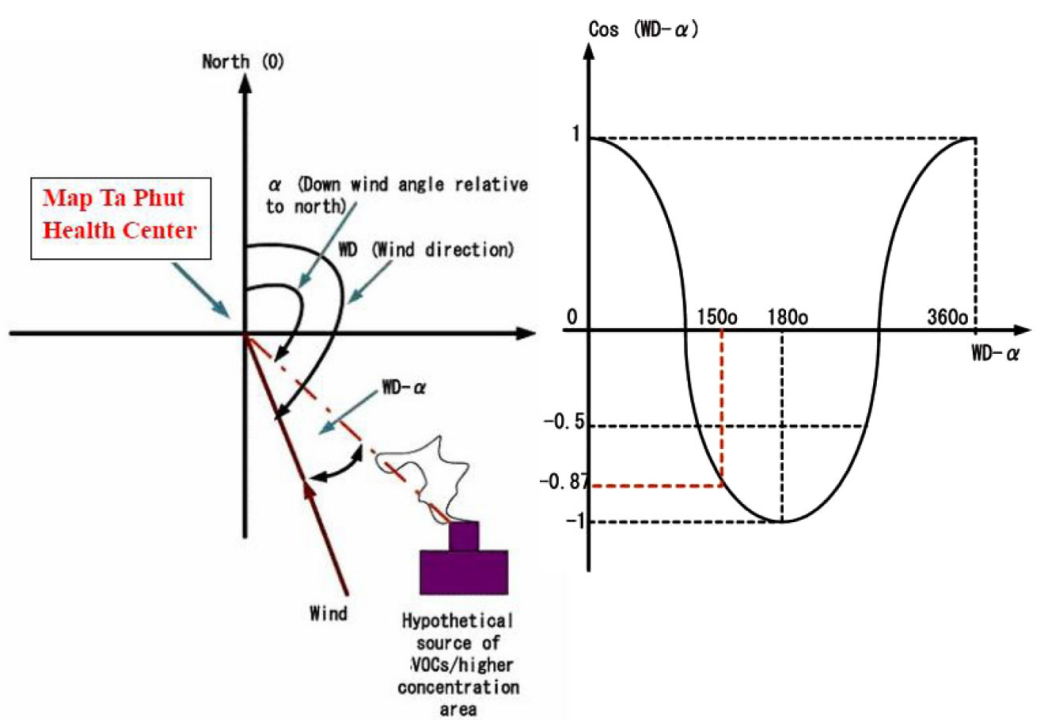

Figure 3: Systematic diagram of the effect of wind direction on a monitoring site.

source strength - wind direction relationship can be represented graphically by plotting the $R$-value of $\operatorname{LnP}$ (natural logarithm of partial pressure) vs Cos(WD- $\alpha$ ) against downwind angle $(\alpha)$ during the monitoring period. To apply this relationship, the measured atmospheric concentrations must be expressed as partial pressures $(P)$, which can be converted through the use of the ideal gas law with a temperature correction [7].

\section{Results and discussion}

It is well known that several tropospheric trace gases such as $\mathrm{O}_{3}, \mathrm{SO}_{2}, \mathrm{NO}_{\mathrm{x}}$ and $\mathrm{CO}$ are anthropogenic, and causing adverse health effects among residents from communities surrounding chemical industrial complexes. As a consequence, it seems reasonable to conduct a long term monitoring as a prevention method against accidental leakage of these toxic chemicals. It is also interesting to note that other trace gases such as $\mathrm{N}_{2} \mathrm{O}$ and $\mathrm{CH}_{4}$ have global warming potential (GWP) of 310 and 21 respectively. Since GWP is a measure of how much a given mass of greenhouse gas is estimated to contribute to global warming, the relatively high GWP of trace gases raised concerns on its impacts on climate change as well as its high potential of adverse public health. For decades, several attempts have been made to both qualitatively and quantitatively identify the potential emission sources of trace gases by using advance statistical models. In order to identify sources, chemical mass balance (CMB) model can be applied to the observed target compound data. CMB approaches are based on the idea that the time dependence of chemical species at the receptor site will be the same for species from the same source. Chemical species are measured in a large 
number of samples gathered at a single receptor site over time. Species of similar variability are grouped together in a minimum number of factors that explain the variability of data set. It is assumed that each factor is associated with a source or source type. However, the method has some limitations in that it can recognize at most only about eight individual source categories in any studies, and poor discrimination of closely related source categories is commonly found. A further disadvantage of multivariate factor analysis is that large numbers of ambient air samples must be collected and analyzed (usually at least 50) and the statistically independent source tracers are required for each major source type. In contrast to CMB model, a trigonometric technique such as CWD model is preferable since it requires no qualitative and quantitative insights of the sources of certain chemical species, and thus overcome the limitations of CMB. The aim of CWD is to identify the "direction" of major sources of air pollutant emissions.

As illustrated in Figure 4, the $R$-values of gaseous $\mathrm{SO}_{2}, \mathrm{NO}, \mathrm{NO}_{2}, \mathrm{NO}_{\mathrm{x}}$ and $\mathrm{O}_{3}$ measured at POS and ITS tended to be higher than those of trace gases detected at other sites. Significant positive correlations $(\mathrm{p}<0.05)$ were found in downwind angles ranging from $180^{\circ}$ to $240^{\circ}$ for $\mathrm{SO}_{2}$ monitored at POS and ITS, suggesting the presence of stationary sources located in south-westerly areas (i.e. IRPC industrial estate (IIE)). It is well known that exposure to high level of $\mathrm{SO}_{2}$ can cause breathing problems, respiratory illness, changes in the lung's defenses, and worsening respiratory and cardiovascular disease. According to the U.S. Environmental Protection Agency (EPA) science assessment, human exposure to $\mathrm{SO}_{2}$ concentration as low as $400 \mathrm{ppb}$ can cause respiratory effects. Furthermore, the recent epidemiologic studies revealed the $\mathrm{SO}_{2}$-related respiratory effects observed in areas where the highest ambient $\mathrm{SO}_{2}$ content was lower than 140 ppbv (i.e. the current 24-h average National Ambient Air Quality Standards (NAQQS)). However, it is important to note that the annual average of $\mathrm{SO}_{2}$ detected at POS and ITS were $23 \pm 34$ and $21 \pm 28$ ppbv respectively, which are defined as "good air quality" according to Air Quality Index (AQI) of Pollution Control Department (PCD) of Thailand. Electrical power plant powered by bituminous coal coupled and heavy oil combustion are considered as $\mathrm{SO}_{2}$ major emission sources from IIE. In addition, the annual atmospheric concentrations of $\mathrm{NO}_{\mathrm{x}}$ and $\mathrm{O}_{3}$ detected at POS and ITS were $19 \pm 20$ and $15 \pm 14 \mathrm{ppbv}$, which were 4.5 and 5.7 times lower than the good air quality standard defined by PCD (i.e. $85 \mathrm{ppbv}$ ). Since the highest $R$-values of $\mathrm{NO}, \mathrm{NO}_{2}$ and $\mathrm{NO}_{\mathrm{x}}$ were observed in downwind angles ranged from $180^{\circ}$ to $210^{\circ}$, it is safely to say that IIE play a significant contribution on emission source strengths of $\mathrm{NO}, \mathrm{NO}_{2}$ and $\mathrm{NO}_{\mathrm{X}}$ as well as $\mathrm{SO}_{2}$. As a consequence, one can conclude that POS and ITS are suitable as trace gas observatory sites for accidental leakage early warning system in residential zone adjacent to IIE.

These findings, coupled with the plot of $R$-value of $\operatorname{Cos}(\mathrm{WD}-\alpha)$ vs $\operatorname{Ln} P$ against the downwind angle $(\alpha)$ of trace gases at MHS, corresponding to the highest $R$-value when $\alpha$ ranged from $220^{\circ}-250^{\circ}$ (i.e. southwestern side of MHS) and thus emphasizing that MIE is most likely to be the major emission source of $\mathrm{SO}_{2}$ in Map Ta Phut residential area. The wind direction contributing toward emission source strength events in MIE and IIE are best visualized through the 

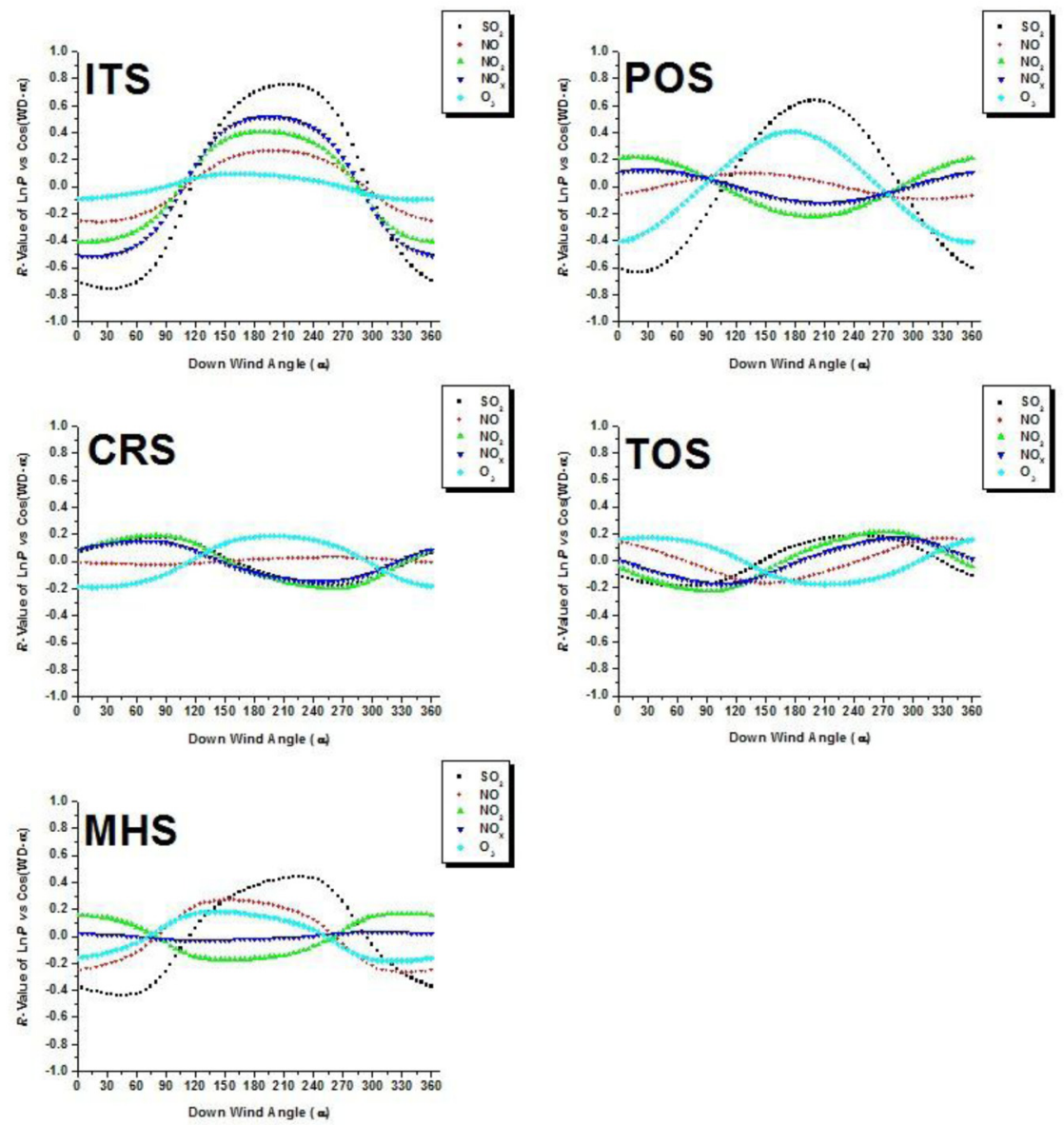

Figure 4: Relationship between downwind angle and $R$-value of $\operatorname{Ln} P$ vs $\operatorname{Cos}(\mathrm{WD}-\alpha$ of trace gases at ITSS, POS, CRS, TOS and MHS.

plot of $R$-value of $\operatorname{Cos}(\mathrm{WD}-\alpha)$ vs $\operatorname{Ln} P$ against the downwind angle $(\alpha)$. This model's ability to visually quantify the direction of LRAT of polychlorinated biphenyls (PCBs) has been demonstrated previously [6]. The study reported here has presented how the model has been extended to identify the direction of emission source of trace gases at five trace gas observatory sites of Rayong province. Owing to the complicated nature of emission source strength and atmospheric chemistry of trace gases, simulation of the exact wind direction of air mass bringing trace gases from the source region was difficult. However, the results have provided a clear assessment of POS, ITS and MHS, which can be used as trace gases accidental leakage early warning site for IIE and MIE respectively. In addition, Figure 4 shows the relatively low $R$-values of all trace 
gases in comparison with those of POS, ITS and MHS. This can be explained by more complicated emission sources of trace gases in MIE compared with those of POS and ITS, which has only one major emission source from IRPC's petrochemical production. Furthermore, it is also interesting to note that significant positive correlations $(\mathrm{p}<0.05)$ were found in downwind angles ranging from $240^{\circ}$ to $270^{\circ}$ (i.e. SW sector) and $60^{\circ}$ to $90^{\circ}$ (i.e. NE sector) for $\mathrm{SO}_{2}, \mathrm{NO}_{2}, \mathrm{NO}_{\mathrm{x}}$ monitored at TOS and CRS respectively. Since the positions of MIE is located at southwest and northeast of TOS and CRS respectively, it appears reasonable to assume that MIE could play an important role as major emission sources of trace gases in Map Ta Phut residential zone.

In this study, the Probability Density Function (PDF), which is a function of a continuous random variable, was calculated to find the point of normal distributions curve of trace gas concentrations collected at ITS, POS, MHS and TOS. PDF can be calculated by using eqn (1) as described below:

$$
y=\frac{1}{\sigma \sqrt{2 \pi}} \exp \left(\frac{-(x-\mu)^{2}}{2 \sigma^{2}}\right)
$$

where $y, x, \mu$ and $\sigma$ are PDF, trace gas concentration, annual average of trace gas concentration and standard deviation, respectively.

As shown in Figure 5, the normal distribution curves of $\mathrm{NO}$ and $\mathrm{SO}_{2}$ collected at ITS and POS had $\sigma$ values lower than those of MHS and TOS, respectively. This can be explained by a higher degree of inconsistency of emission source strengths over IRPC industrial estate, possibly due to complicated fuel consumption rates that occurred inside the factory. It is also interesting to address that the inflection points of normal distribution curves of $\mathrm{O}_{3}$ detected at TOS were very far from $\mu$ in comparison with those of ITS, POS and MHS. Since the distance between the inflection points and $\mu$ represents the magnitude of data dispersions, it appears reasonable to assume that ITS and POS were influenced by relatively more consistent $\mathrm{O}_{3}$ emission sources than those of TOS.

\section{Conclusions}

$\mathrm{SO}_{2}, \mathrm{NO}, \mathrm{NO}_{2}, \mathrm{NO}_{\mathrm{x}}$ and $\mathrm{O}_{3}$ were monitored at five observatory sites adjacent to Map Ta Phut and IRPC industrial estate and the cosine wind direction (CWD) model was studied. The prediction of wind direction by CWD model at five observatory sites, reveals that TOS, CRS, MHS and POS, ITS are suitable as trace gas observatory sites for accidental leakage early warning system in residential zone adjacent to MIE and IIE in that order. In addition, the relatively low $R$-value of trace gases detected at TOS, CRS and MHS indicated higher number of emission sources found at MIE. 

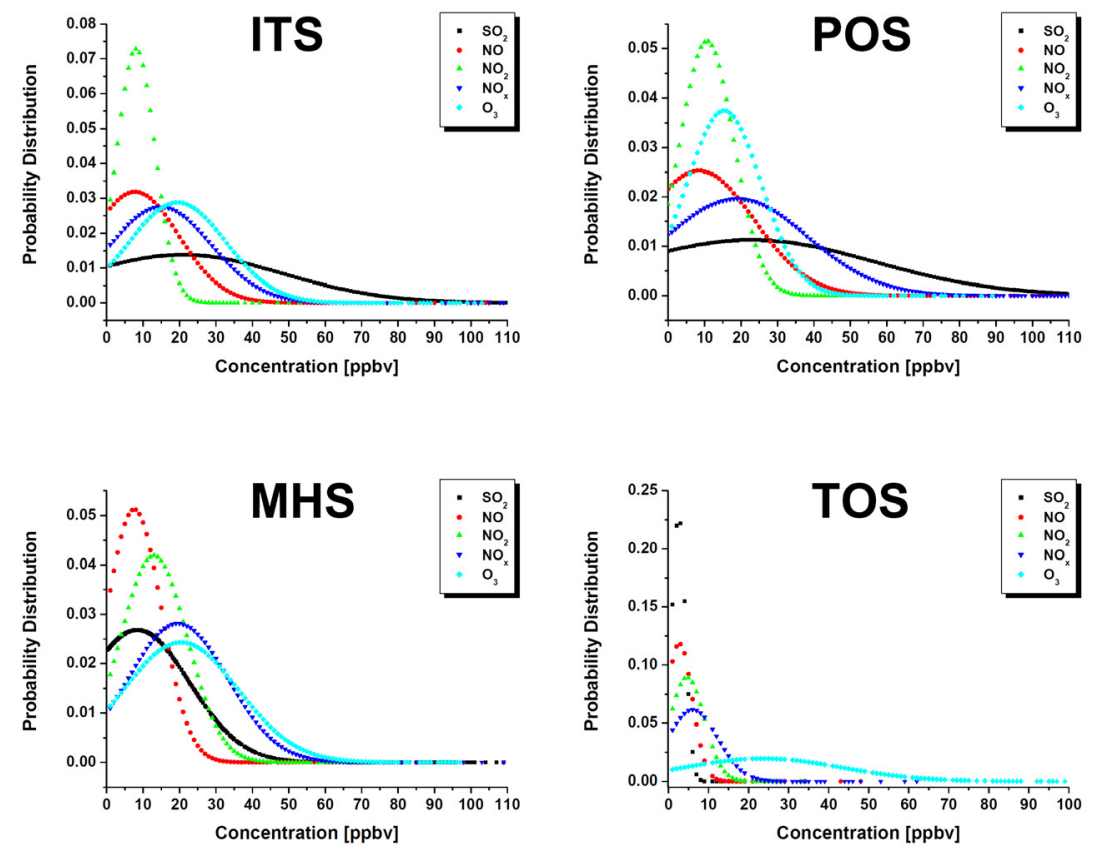

Figure 5: $\quad$ Probability distribution of trace gases at ITS, POS, MHS and TOS.

\section{Acknowledgements}

The authors thank IRPC Co., Ltd coupled with Pollution Control Department of Thailand for their contribution in providing the facility to collect data and National Center of Excellence for Environmental and Hazardous Waste Management-PSU Satellite Center, Prince of Songkla University for financial support.

\section{References}

[1] Brunciak, P. A., Dachs, J., Gigliotti, C. L., Nelson, E. D and Eisenreich, S. J., Atmospheric polychlorinated biphenyl concentrations and apparent degradation in coastal New Jersey. Atmospheric Environment, 35, pp. $3325-$ 2229, 2001.

[2] Hornbuckle, K. C., Achman, D. R and Eisenreich, S. J., Overwater and overland polychlorinated biphenyls in Green Bay, Lake Michigan. Environmental Science \& Technology, 27, pp 87-98, 1993.

[3] Offenberg, J. H and Baker, J. E., Influence of Baltimore's urban atmosphere on organic contaminants over the northern Chesapeake Bay. Journal of the Air \& Waste Management Association, 49, pp 959-965, 1999. 
[4] Currado, G. $M$ and Harrad, S., Factors influencing atmospheric concentrations of polychlorinated biphenyls in Birmingham, U.K. Environmental Science \& Technology, 34, pp 78-82, 2000.

[5] Simcik, M. F., Zhang, H., Eisenreich, S. J and Franz, T. F., Urban Contamination of the Chicago/Coastal Lake Michigan Atmosphere by PCBs and PAHs during AEOLOS. Environmental Science \& Technology, 31, pp 2141-2147, 1997.

[6] Harrad, S and Mao, H., Atmospheric PCBs and organochlorine pesticides in Birmingham, UK: concentrations, sources, temporal and seasonal trends. Atmospheric Environment, 38(10), pp 1437-1445, 2004.

[7] Cortes, D. R., Basu, I., Sweet, C. W., Brice, K. A., Hoff, R. M and Hites, R. A., Temporal Trends in gas-phase concentrations of chlorinated pesticides measured at the shores of the Great Lakes. Environmental Science \& Technology, 32, pp 1920-1927, 1998. 